\title{
LAS RAÍCES SIMBOLISTAS DEL ART NOUVEAU*
}

\author{
Francesc FONTBONA \\ Reial Acadèmia Catalana de Belles Arts de Sant Jordi, Barcelona
}

Samuel Bing abrió una tienda de decoración moderna en París, en Diciembre de 1895. La llamó «L'Art Nouveau», y ya en su exposición inaugural había cosas de Brangwyn, metales de Benson, habitaciones de Van de Velde, pinturas de Vuillard, Besnard, Denis, vidrios de Tiffany y otras piezas de Bonnard, Ibels, Ranson... ${ }^{1}$ La difusión de todas aquellas cosas a través de una tienda especializada creó una espectativa especial por un tipo de arte cuyos elementos no formaban todavía una unidad estética etiquetada, pero que pronto la formarían, y precisamente bajo la denominación del establecimiento que las comercializaba. Se hablaría pues, cada vez más, del estilo Art Nouveau.

Bing (Hamburgo 1838-Vaucresson 1905) era un comerciante de objetos de arte, especialista primero en piezas orientales, y convertido luego en marchante de modernidades a través de aquella tienda que había abierto en París, que pronto adquiriría un carácter carismático. Aunque la pretensión de Bing era difundir todo tipo de arte moderno, no tardó en identificarse el título de su establecimiento con un estilo decorativo determinado, que fascinó rápidamente al público con sus elementos sensuales, basados en formas vegetales, delicuescentes, de trazos curvilíneos y muy a menudo asimétricos, y con figuras fantásticas, legendarias o

* Las obras concretas citadas en el texto, que en la conferencia se proyectaron en diapositiva, hay que considerarlas ejemplos seleccionados de lo que se está exponiendo, y en muchas ocasiones habrían podido ser substituidas por otras equivalentes. La abreviatura MNAC corresponde a Museu Nacional d'Art de Catalunya, de Barcelona.

'Hay ya mucho publicado sobre esto, pero véase, por ejemplo, Amaya 1966, págs. 108-111. 
medievalizantes. Las citadas líneas curvas adoptaban a menudo ya forma de un látigo en acción, por lo que fueron definidas como coup-de-fouet, que significaba «latigazo» en francés, expresión con la que muchos caracterizaban el aspecto más immediato del Art Nouveau.

El estilo del Art Nouveau, identificado también con la denominación Modern Style - «arte nuevo» o «estilo moderno», la idea era la misma- era agradable a la vista y despertaba en el espectador evocaciones fantasiosas ${ }^{2}$. Era un arte que en vez de representar retazos de la vida cotidiana, como hacía el Naturalismo, se basaba en la fantasía, especialmente la derivada del mundo de las hadas y de los cuentos ancestrales. Si primero era visto, por ejemplo en Inglaterra, como un estilo francés, ajeno a la modernidad autóctona (Battersby 1969, pág. 11), pronto se difundió enormemente gracias a que triunfó en la Exposición Universal de París de 1900, punto de cita masivo de ciudadanos de todo el mundo, y fue tal su triunfo que en seguida se vulgarizó a gran escala. Como ha dicho alguien, «en tres o cuatro años la expresión «Modern Style» vino a designar todos los hallazgos Art Nouveau que habían sido reducidos a la vulgaridad a través de la producción en masa» (Julian, 1974, pág. 111), y hasta hay quien opina que la Exposición Universal de 1900 «fué a la vez el apogeo y el final del Art Nouveau» (Battersby 1969, pág. 25), precisamente por la vulgarización que desencadenó de este estilo.

Era la época en que la decoración de un establecimiento comercial, como era el caso de la tienda de música Cassadó \& Moreu de Barcelona (1900), se resolvía totalmente mediante elementos ornamentales y de mobiliario de este estilo -hoy dispersos-, y en este caso concreto además enriquecido con pinturas murales al óleo de un joven artista, Pau Roig (Lohengrin, Orfeo y Sinfonía pastoral), hoy conservadas en el Departament de Cultura de la Generalitat de Catalunya. Murales de este tipo proliferaron bastante, incluso destinados a entidades que poco tenían que ver con los mundos de ensueño que representaban, como el que Alexandre de Riquer hizo para el Institut Industrial de Terrassa, en 1901, hoy en el Museu Alegre de Sagrera de aquella ciudad cuya fortuna tuvo un fuerte carácter industrial textil.

Riquer, artista polifacético, personificación en sí mismo del anhelo de la integración de las artes, tan en voga en la época, actuó mucho también en el campo de las artes gráficas, uno de los más receptivos a utilizar el estilo Art Nouveau. Riquer diseñó todo tipo de cosas en este ámbito: desde emblemas para entidades (Societat Coral Catalunya Nova, 1900), hasta recordatorios funerarios

${ }^{2}$ Durante un tiempo, tras el estallido afortunado del concepto Art Nouveau en Francia, incluso en aquel país prevaleció la denominación «Style Moderne» (Bayard 1919). 
(como el de Consolació Company de Canals, de 1901), pasando por una de sus grandes especialidades, el ex-libris, pequeña marca de propiedad de libros, que en aquella época estaba tan de moda en toda la Europa culta que era objeto ya incluso de coleccionismo. Los ex-libris de Riquer, los primeros de los cuales se reunirían en un bellísimo volumen en 1903, se resolvían habitualmente, como el resto de sus diseños gráficos, siguiendo las pautas del Art Nouveau.

La moda del ex-librismo se desarrolló a través de varios otros artistas, como Josep Triadó, que también reunió sus marcas en un libro (1906). De él es igualmente el diseño de la encuadernación industrial de una publicación especializada, de gran rigor y belleza, la «Revista Ibérica de Ex Libris» (1903). Y aunque mayoritariamente la influencia del Art Nouveau en España se manifestó en Cataluña, también podemos hallar ex-libris de estilo Art Nouveau en la producción de artistas de otros puntos de la península, como son los casos del andaluz recriado en Castilla Eulogio Varela, el aragonés José Galiay o el alcoyano Gumersindo Molina, de labor breve pero representativa.

La fuerte tendencia al Art Nouveau que se observaba en muchos artistas de aquella generación respondía a veces claramente al impulso de la moda impuesta, como se ha visto, por el éxito que aquel estilo obtuvo gracias a su difusión a través de la Exposición Universal de París. Que muy a menudo obedecía más a una moda que a una profunda convicción estética lo atestigua precisamente uno de los exlibristas catalanes más importantes del momento -que también reunió su libro de marcas, en 1907-, Joaquim Renart, quien en su madurez escribiría en su diario que en aquella época no podía hacerse ningún dibujo decorativo sin inspirarse en las propuestas de la revista inglesa «The Studio» o de las láminas de los cuadernos Dekorative Vorbilder, publicados en Stuttgart, difusores a escala internacional de aquel estilo (Renart 1995, vol. I, pàgs. 327-328).

Dentro de la atmósfera Art Nouveau cabían realizaciones gráficas de muy distinta categoría: desde la edición de libros exquisitamente minoritarios, como Boires baixes (1902), de Josep Maria Roviralta, con ilustraciones de Lluís Bonnin y pàginas musicales de Enric Granados, hasta la imagen de los distintos volúmenes de una revista de gran altura intelectual, como «Joventut» (1900-06), con cubiertas y diseños de Adrià Gual, Apeles Mestres, Sebastià Junyent, o los ya citados Riquer -que era el director artístico- y Triadó. Pero por otro lado el Art Nouveau inundaba también impresos catalanes de difusión masiva, como un conocido calendario de Gaspar Camps, de 1901, el prospecto de la casa de modas barcelonesa de Pilar Pérez (1903), el programa de la Temporada de Invierno del Teatro del Liceo de Barcelona (1906), el prospecto de la casa de ropa Riera Hnos. también de Barcelona (1906), o el de la Sastreria New England de igual localiza- 
ción (1906-07), dibujado éste por el citado Triadó; y tal fué la vulgarización que alcanzó aquel estilo, que hasta lo encontraremos en los billetes de una plaza de Toros tan alejada del mundo catalán como la de de Zafra, y tan tarde como en 1909.

El estilo Art Nouveau servía ya para todo y a lo largo de la primera década del siglo fué cada vez más omnipresente. Que se trataba de un uso generalizado lo atestigua el hecho de que los impresores que hicieron los ejemplos barceloneses que he mencionado fueron muy diversos (L'Avenç, Jepús, Casamajó, Elzeviriana) y que por lo tanto aquel estilo no era cosa ya de ningún especialista.

El campo de la decoración era también muy propicio al Art Nouveau. Los jarrones decorativos de los años en que estaba en su esplendor podían ser antropomorfos y jugar con las sinuosidades de las vestimentas de las figuras que les daban cuerpo, como queda bien manifiesto en una famosa pieza de Dionís Renart (Gerro, c1900, Museu d'Art Modern de Barcelona-MNAC).

Por su parte el mobiliario jugaba con arabescos semejantes, y a veces se potenciaban a través del perfeccionamiento de técnicas refinadisimas y exquisitas, como la marqueteria, en la que destacó un mallorquín establecido en Barcelona, Gaspar Homar, que solía interpretar diseños de Josep Pey, como en los muebles de la casa Lleó \& Morera de Barcelona (c1901, MAMB/MNAC). A Pey, dibujante todo terreno, lo podemos encontrar también colaborando con el ceramista Antoni Serra Fiter realizando obras de porcelana a gran fuego como el jarron de la Anunciación (1907, MAMB-MNAC), directamente inspirado en un óleo de otro artista polifacético, Sebastià Junyent (Ave Maria, 1902, colección privada).

La llamada Casa-Museo Modernista, de Novelda, inaugurada en 1905 como residencia de una familia rica, es un buen ejemplo de hasta que punto en aquellos años lo más moderno era diseñar, decorar y amueblar un edificio siguiendo las pautas del Art Nouveau, algo que a buen seguro un lustro antes no habría sido así pese a que el Art Nouveau ya existía.

La presencia del Art Nouveau, pues, era masiva y a todos los niveles. Lo hallaremos en joyas costosísimas, técnicamente muy complejas, con sus esmaltes y su especial cincelado, creadas por Lluís Masriera desde los primeros años del siglo XX (Penjoll de Sant Jordi, c1901). Masriera, otro artista total -era joyero, pintor, dramaturgo, escenógrafo, director teatral-, introdujo la imagen estilizada de hadas, ninfas, personajes legendarios o bellos insectos en sus preciosos bro-

${ }^{3}$ Hoy excelentemente mantenida como museo y centro cultural por la Fundación CAM. 
ches, colgantes, pendientes, anillos, etc., como lo había hecho Lalique en Francia. Y también como él presentó todas estas figuras arropadas por formas vegetales sinuosas en oro y esmaltes de riquísimo cromatismo.

Y al lado de estas miniaturas que tenian lógicamente un círculo muy limitado de «consumidores», los escultores también concebían sus composiciones dentro de los mismos parámetros. Josep Llimona labró su famoso Desconsol (1903, diversos ejemplares), utilizando una figura femenina desnuda cuyos largos cabellos adoptan elegantemente las formas curvilíneas típicas del Art Nouveau. Enric Clarasó, en su famosa Eva (1904, MAM-MNAC), jugó con los mismos elementos. Miquel Blay, en su grupo Perseguint la il?lusió (c1903, Barcelona, MAMMNAC), combina bronce y mármol para representar el anhelo del hombre para alcanzar su ilusión, lo que da pie al escultor a plasmar lo volátil a través de formas dinámicas y huidizas del mismo estilo. Hasta el joven Josep Clarà, antes de convertirse en uno de los paradigmas del nuevo clasicismo escultórico del siglo XX, el Noucentisme, representó al Éxtasis (1903, Barcelona, colección Domingo Cirera), mediante una ensoñada figura femenina delicuescentemente labrada, cuyos contornos, pese a ser marmóreos, se nos aparecen como brumosos.

Pero había todavía una escultura Art Nouveau más visible a todos los públicos. En los principales edificios del momento, grandes grupos escultóricos de gusto similar se entremezclaban con la arquitectura: Eusebi Arnau narró un cuento entero en piedra -La dida de l'infant del Rei-, en las sobrepuertas del piso principal de la antes aludida casa Lleó i Morera de Barcelona (1904-05), o pobló de alegorias de la música el escenario del Palau de la Música Catalana de la misma ciudad (1907-10), que en este caso se fundían con otra técnica muy distinta, el mosaico, que daba forma a los vestidos de las figuras, mientras la escultura daba cuerpo a torsos y cabezas. En el mismo Palau, Diego Masana y el joven Pablo Gargallo -el futuro pionero de la Vanguardia escultórica europea- modelaron el gran arco de la embocadura del mismo escenario, jugando perpetuamente con formas fugaces que traducían nubes, árboles, templos, estatuas y walkirias en plena cabalgata $(1907-10)^{4}$.

Y no era necesario ir a uno de estos edificios singulares para sentir la presencia del Art Nouveau más corpóreo: en muchas casas particuares, modestas jardineras y bibelots de todo tipo eran asimismo de estilo Art Nouveau, por obra y gracia del escultor Lambert Escaler, que las producía masivamente desde 1903, ejemplo que fue seguido durante un tiempo por muchos otros modelistas.

${ }^{4}$ Los dos edificios citados en este párrafo eran obra del arquitecto Lluís Domènech i Montaner, a quien se debe sin duda la idea global de los proyectos ejecutados luego por los escultores mencionados. 
Todo esto era el Art Nouveau triunfante y a la vez decadente, el que gracias al altavoz de la Exposición Universal de París del 1900 se había divulgado a todos los niveles. Pero este estilo, ahora mayoritariamente decorativo, que podia parecer hijo de una pura superficialidad simplemente grata a la vista, no había surgido de la nada, sinó que se nutría, en realidad, de formas que pertenecían a un profundo movimiento cultural del ochocientos tardío. Este movimiento era el Simbolismo.

El éxito masivo del Art Nouveau era, como se ha podido ver, bastante posterior a la instalación de la tienda Bing que le daría nombre. Si ésta se creó en 1895 y el lanzamiento del estilo a todos los niveles no llega hasta después de 1900 , vemos que por lo menos hubo cinco años de incubación, durante los cuales el establecimiento de Bing, todavía ajeno al tumulto de los visitantes de una Exposición Universal, seleccionó objetos y artistas para dar cuerpo a la oferta que luego estallaría espectacularmente de la mano de aquella magna feria. El cliente de Bing en aquellos primeros años era todavia un refinado más o menos snob, que se dejaba cautivar por objetos y elementos muy selectos, hijos de la inspiración de artistas de gran sensibilidad, inquietud estética y originalidad. Como su nombre indicaba, el Art Nouveau de Bing ofertaba el «arte nuevo», y lo ponía a disposición de un público todavía muy minoritario, en sólo un primer y tímido paso para difundirlo -tal vez sin imaginarse hasta qué punto- fuera de los círculos estrictos de sus creadores.

Por todo ello cuando nos acercamos a obras artísticas de fin de siglo como la pintura de Adrià Gual Santa Cecília (c1900, colección privada), que tiene todo el aspecto del Art Nouveau, tendremos que pensar, antes que en este concepto, que se trata de creaciones no hijas de una simple moda sino genuinamente partícipes de la sensibilidad de un verdadero movimiento cultural de gran densidad y alcance, el Simbolismo.

También en el Simbolismo más puro, antes de su vulgarización Art Nouveau, las artes gráficas fueron canales importantes de expresión. El citado Adrià Gual -otro artista versátil: poeta, pintor, dramaturgo y grafista- publicó obras decoradas en este estilo como Llibre d'hores (1899); Santiago Rusiñol hacía en el mismo estilo los carteles para la representación teatral del Interior de Maurice Maeterlinck (1899) y para su propio libro Fulls de la vida (1898), y Alexandre de Riquer ya había utilizado aquellas formas antes de que fueran tan populares, en carteles como Salón Pedal (1899), Mosaicos hidráulicos Órsola, Solà y Cia (1898) o A. y E. F. Napoleón (1895), lo que nos da que pensar que utilizar grandes cromolitografías simbolistas para anunciar, todavía en el siglo XIX, un local ciclista, una fábrica de baldosas o un fotógrafo, como en los tres casos 
mencionados, denota que ya existia una cierta sintonía entre aquel estilo exquisito y la sociedad más prosaica de su tiempo; y no sólo en Cataluña, sinó también en otros lugares, como Madrid, pues allí estaba radicado el citado Salón Pedal, y también allí aparecía la revista «Blanco y Negro», en la que el dibujante Eugenio Chiorino publicaba «dibujos prerrafaelistas» en fechas bastante tempranas para tratarse de obras destinadas al gran público (así la Natividad de Nuestra Señora, del 11 de Septiembre de 1897).

En este campo de las artes gráficas, ya detectaremos una presencia simbolista notable incluso en publicaciones no especialmente intelectualizadas. Es el caso de Joan Brull ilustrando la portada de una revista elegantemente mundana como «Hispania», de Barcelona, en 1899; pero era más frecuente que dibujos de este estilo aparecieran en impresos más ligados al mundo cultural innovador, como los de Josep Maria Roviralta en la revista barcelonesa «Luz» en 1897 y 1898. Alexandre de Riquer, al que ya hemos visto protagonizando la época Art Nouveau, ya tenia una fuerte actividad años antes cuando su obra era puramente simbolista, y con ella ilustraba catálogos de exposiciones de arte como la del Cercle Artístic de Sant Lluc (1897) o portadas de ediciones de gran pretensión cultural como la de la ópera La fada de Jaume Massó y Enric Morera (1897), cuya representación en Sitges fué una especie de manifiesto vivo del movimiento modernista catalán.

La pintura, la más conocida de las artes plásticas, sirvió muy a menudo de plataforma para la estética simbolista. En la España no catalana la pintura de este tipo es tardía, en general posterior al cambio de siglo, como por ejemplo el Reinaldo en el bosque encantado (1903), de Eduardo Chicharro (Madrid, Ministerio de Asuntos Exteriores). En Cataluña en cambio se cultivó ya a lo largo de toda la década de los noventa. Aquel Joan Brull al que habíamos visto ilustrando revistas, antes se había hecho especialmente famoso con una pintura, Ensomni (1898, MAMB-MNAC), que jugaba más o menos sinceramente con los mitos del Simbolismo: una ninfa soñando junto al estanque de un bosque fantástico. Josep Maria Tamburini traducía al óleo un cuento ambientado en una hipotética Edad Media (Conte blau, 1898, Madrid, Palacio Real), igual que antes se había recreado en situaciones semejantes a las de Brull, en Harmonies del bosc (1896, MAMB-MNAC), y más atrás todavía había dado vida a la literaria Ofèlia (1894-96, Barcelona, colección particular)5. El omnipresente Alexandre de Riquer tambien había trasmitido su particular mundo estético en pinturas como

5 En la época del triunfo del Art Nouveau, Tamburini todavía cultivaba su versión del Simbolismo en obras como L'Anunciació (1904, Barcelona, colección particular). 
Poesia y Música (1897, Barcelona, colección particular) o unas Cuatro Estaciones (1897, Barcelona, colección particular), y lo mismo diríamos de otro puntal de esta tendencia, Adrià Gual, con obras como La rosada (1897, MAMB$\mathrm{MNAC}$ ), en la que hasta el marco encierra un poema, o L'àngel de la nit (1896, can Graupere).

El Simbolismo fue un movimiento cultural interdisciplinario que se expresaba más por lo que sugeria que por lo que describía. En la época en que el Naturalismo o incluso una de sus derivaciones más afortunadas, el Impresionismo, cargaban el énfasis de su creatividad en la representación de la realidad externa, otros artistas se sintieron más llamados a crear un mundo imaginado que explicase mejor verdades profundas. En este punto el Simbolismo podía tener, y tenía, una cierta proximidad con el arte religioso más sincero, y por ello no es extraño que en la obra de pintores militantemente cristianos como Joan Llimona (Mural de la cúpula del Camarín del monasterio de Montserrat, 189698) haya cierto eco o concomitancia evidente con el Simbolismo.

Más atrás en el tiempo, el ya citado Santiago Rusiñol -escritor, pintor y lider modernista-, que paradójicamente provenía del mundo próximo al Impresionismo, había protagonizado una de las más tempranas versiones, a este lado de los Pirineos ${ }^{6}$, de Simbolismo pictórico, en el tríptico mural que pintó para sí mismo, La Musica, La Poesía y La Pintura (1894-95, Sitges, Cau Ferrat).

Cronológicamente hablando Simbolismo es un concepto que tiene su gran año en 1891, como dijo taxativamente Ernest Raynaud. Sin embargo, en aquellos años hablar de Simbolismo -dado ya por muerto en 1886! por uno de sus definidores, Jean Moréas- era mucho más referirse al mundo literario que al plástico, y en este contexto ideológico el pintor més cercano a aquel movimiento era Paul Gauguin, cuyo mundo, evidentemente cargado de intención profunda, se traducía en un estilo radicalmente innovador, mucho más que el de la mayoría de simbolistas, que se expresaban a través de lenguajes más académicos, y que no constituían un grupo concreto sinó una tendencia. Este estilo, conocido como Sintetismo, en España tuvo también sus ecos esporádicos -como la acuarela de Ignacio Zuloaga Au bord de l'Oise (c1894, Barcelona, Gabinet de Dibuixos i Gravats del MNAC)-, y una versión muy directa, la del íntimo amigo vasco de

"De hecho uno de los grandes creadores de la iconografía de los primeros poetas simbolistas franceses -Rimbaud, Anatole France, Baju- fue un español, Manuel Luque, de Almería, que después de colaborar en «Madrid Cómico» pasó a Francia y dibujó caricaturas en las mejores tribunas del género en París, a fines de los ochenta. Luque, sin embargo, no tenía nada que ver con el estilo del Simbolismo, por lo que no se le puede etiquetar así. 
Gauguin, Paco Durrio, que en sus diversas joyas de hacia 1895-96 traducía en oro figuras primitivistas semejantes a las de su amigo, antes de las cuales en España no hallaremos producciones tan creativas e imaginativas más que en la obra genial de Antoni Gaudí, cuyo gran Dragón en hierro forjado que sirve de puerta a los Pabellones Güell de Barcelona (1885), podía haber sido el gran y original punto de partida de un Simbolismo plástico autóctono si no fuera por que Gaudí siempre fué por libre y no estaba enrolado en ningún movimiento artístico organizado.

Recapitulando, el Art Nouveau fue un estilo artístico de alcance masivo, puesto de moda hasta la vulgarización, por la Exposición Universal de París de 1900. Se manifestaba especialmente en las artes aplicadas: decoración, mobiliario, artes gráficas... y su vocabulario plástico lo constituían formas voluptuosas, elaboradas con pretextos vegetales y elementos naturales insólitos y coloristas, además de la presencia a veces de figuras antropomorfas, casi siempre femeninas, procedentes del mundo de la fábula.

Este vocabulario formal, utilizado hasta la saciedad en la primera dècada del siglo XX, para adornar los elementos más cotidianos, desde ceniceros hasta tickets de espectáculos, no era sin embargo una creación de los decoradores al servicio de la Expo de París 1900, sinó que surgía de la iconografía de uno de los estilos más exigentes y profundos del ochocientos final, el Simbolismo, uno de los componentes básicos de este movimiento renovador que en Cataluña fué llamado, precisamente por su voluntad de modernización, Modernisme.

Los artistas simbolistas representaron en su gran época, los años ochenta y sobre todo noventa del siglo XIX, la vanguardia cultural del mundo occidental, y aunque algunos de ellos se aprovecharon del éxito popular alcanzado por su estilo tras 1900, otros, los más comprometidos con la modernidad, abjuraron de aquel estilo ya desactivado como revulsivo cultural, que en su caida en los círculos intelectuales arrastró también en Cataluña al descrédito la palabra Modernisme, cuando la mayoría lo identificaba ya, abusivamente, con la anécdota Art Nouveau.

\section{REFERENCIAS BIBLIOGRÁFICAS:}

AmaYa, Mario. 1966. Art Nouveau, Londres, Studio Vista.

BatTersby, Martin. 1969. Art Nouveau, Feltham, Paul Hamlyn. 
BAYARD, Émile. 1919. Le Style Moderne, Paris, Garnier.

Julian, Philippe. 1974. The triumph of Art Nouveau. Paris Exhibition 1900, London, Phaidon.

RENART, Joaquim. 1995. Diari 1918-1961, Barcelona, Curial Edicions Catalanes. 